\title{
Narradoras excêntricas em Uma Duas: a escrita como subsídio à construção da subjetividade feminina no romance de Eliane Brum
}

\author{
Excentric narrators in One Two: the written as a subsidy to the construction of \\ female subjectivity in the novel of Eliane Brum \\ Narradores excéntricos en Uma Duas: la escritura como un subsidio para la construcción \\ de la subjetividad femenina en la novela de Eliane Brum \\ Natacha dos Santos Esteves $\oplus^{1}$ \\ Wilma dos Santos Coqueiro 1 \\ 1 Universidade Estadual do Paraná, Campo Mourão, PR, Brasil.
}

$\diamond$

\begin{abstract}
RESUMO
Partindo de uma contextualização histórica sobre a relação que as mulheres mantinham com a escrita, esse artigo reflete sobre a emergência da voz narrativa feminina no romance contemporâneo Uma Duas, publicado em 2011, pela escritora e jornalista Eliane Brum. Nesse romance de autoria feminina, que apresenta uma conflituosa relação entre mãe e filha, devido a traumas vivenciados por ambas, elas enfrentam os espectros de seus passados ao se tornarem conarradoras de uma história de dor, dilaceramento e feridas jamais cicatrizadas. Em face ao descentramento sofrido por ambas em relação ao lugar social enquanto mulheres marcadas por traumas e abusos, a escrita de suas memórias apresenta um efeito catártico, por meio do qual elas podem construir as suas subjetividades. Os aportes teóricos oriundos dos estudos culturais e da crítica feminista, sobretudo Showalter (1994), Muzart (1985), Zolin (2009a, 2009b), Touraine (2011), Dalcastagné (2012) e Woolf (2014), subsidiarão nossas reflexões.
\end{abstract}

Palavras-chave: Ficção contemporânea de autoria feminina. Eliane Brum. Descentramento. Escrita e subjetividade.

\begin{abstract}
Starting from a historical contextualization about the relationship that women had with writing, this article reflects about the emergence of the female narrative voice in the novel One Two, written by the brazilian journalist Eliane Brum and published in 2011. This novel presents a conflicting relationship between mother and daughter due to traumas experienced in the past, they reveal those traumas as they tell the story as co-narrators of pain, lacerations and wounds never healed. In the face of their decentralization from the social place as women marked by traumas and abuses, the writing of their memories has a cathartic effect, whereby they can construct their subjectivity. The theoretical contributions from cultural studies and feminist critics, especially Showalter (1994), Muzart (1985), Zolin (2009a, 2009b), Touraine (2011), Dalcastagné (2012) and Woolf (2014), will support our reflections.
\end{abstract}

Keywords: Contemporary feminine fiction. Eliane Brum. Decentralization. Writing and subjectivity.

\section{RESUMEN}

Partiendo de una contextualización histórica de la relación que las mujeres tenían con la escritura, este artículo reflexiona sobre el surgimiento de la voz narrativa femenina en la novela contemporánea Uma Duas, publicada en 2011, por la escritora y periodista Eliane Brum. En esta novela de autoría femenina, que presenta una relación conflictiva entre madre e hija, debido al trauma experimentado por ambas, se enfrentan a los espectros de su pasado a medida que se convierten en narradores de una historia de dolor, laceración y heridas sin curar. Frente a la descentralización que sufren tanto en relación con el lugar social como las mujeres marcadas por el trauma y el abuso, la escritura de sus recuerdos tiene un efecto catártico, a través del cual pueden construir su subjetividad. Las contribuciones teóricas de los estudios culturales y la crítica feminista, especialmente Showalter (1994), Muzart (1985), Zolin (2009a, 2009b), Touraine (2011), Dalcastagné (2012) y Woolf (2014) apoyarán nuestras reflexiones.

Palabras clave: Ficción femenina contemporânea. Eliane Brum. Descentralización. Escritura y subjetividad. 


\section{Considerações iniciais sobre o cânone excludente}

Historicamente, a figura feminina foi privada de muitos bens imprescindíveis para a sua constituição enquanto sujeito, sendo submetida a uma posição marginalizada no que tange a todas as relações sociais. Ao indivíduo-mulher foi debitado a responsabilidade da reprodução, da total obediência ao homem (pai, irmão, marido) e das tarefas do lar. Com todo esse apagamento de identidade e ausência de discurso, algumas mulheres recorreram à escrita como uma forma de tentar romper com esse domínio patriarcal, dando voz a personagens fragmentadas e complexas, conforme postula Virginia Woolf, em seu ensaio Um Teto Todo Seu (2014). Nesse movimento de tentar romper com os valores patriarcais e com a organização dos papeis de gêneros, muitos obstáculos - que não diziam respeito à qualidade estética das obras produzidas - foram lançados nas carreiras artísticas de escritoras, desde o Período Elisabetano na literatura britânica até o século XX e, como se verá adiante, também no século XXI.

Seguindo a linha evolutiva da sociedade, muitos pensamentos e valores entram em declínio por não se fazerem mais suficientes e pertinentes para as necessidades da época, como é o caso da visão - misógina - que a sociedade mantinha sobre as mulheres e o próprio papel que elas ocupavam e desenvolviam em suas relações sociais e afetivas. Ainda assim, o Cânone Literário, por um longo tempo, se manteve resistente em reconhecer a relevância e o valor estético-cultural das obras escritas por mulheres. Ora, é de conhecimento comum que “[...] no interior de qualquer formação cultural as camadas dirigentes se valem de diversas formas discursivas e as transformam em ideologia para assegurar o seu domínio" (REIS, 1992, p. 66). Tendo em mente que a LITERATURA não é uma "experiência inofensiva" (CANDIDO, 2011, p. 178), é de se esperar que o patriarcado tenha feito uso dela para assegurar o seu poder hegemônico e é, nesse sentido, que o cânone literário funciona como um agente de manutenção cultural, altamente excludente, filtrando o que determinado grupo de pessoas deve ler e apreciar, categorizando, assim, obras produzidas por mulheres dos séculos anteriores como inferiores. Devido ao seu cunho subjetivo, os críticos as categorizavam como "assuntos domésticos" e realçavam o caráter fragmentário e simples das narrativas.

Mudando um pouco o cenário, no Brasil, ao ter-se em análise os livros didáticos do Ensino Médio e mesmo as obras sobre a história da literatura brasileira de grandes autores como Antonio Candido e Alfredo Bosi, é notável que, praticamente, não há mulheres a serem estudadas no nosso contexto de formação de Literatura Nacional. No século XIX, por exemplo, para nos atermos no campo da ficção, temos autoras de grande expressão literária como Maria Firmina dos Reis (1822-1917) e Júlia Lopes de Almeida (1862-1934). Essa última integrava o grupo de escritores que planejou a criação da Academia Brasileira de Letras, fundada no Rio de Janeiro, em 1897, e o seu nome constava na primeira lista de imortais da Academia. Porém, após a primeira reunião da Academia, o seu nome foi vetado, simplesmente, por ser mulher. Como uma espécie de "prêmio de consolação", no lugar dela entrou o seu marido, Filinto de Almeida, que não tinha produção literária expressiva e marcante como a sua esposa. Apenas 80 anos depois, em 1977, uma mulher ocuparia uma cadeira na Academia Brasileira de Letras e figuraria nas antologias dedicadas ao estudo da história da Literatura brasileira: a cearense Rachel de Queiroz, que também foi a primeira mulher a ser galardoada com o maior prêmio das Literaturas de Língua Portuguesa, o "Prêmio Camões", em 1993.

Desse modo, se ao estudarmos a Literatura de autoria feminina brasileira, temos acesso a escritoras de alta expressão literária como a já citada Rachel de Queiroz e Clarice Lispector; em compensação, há inúmeras escritoras que ficaram de fora, principalmente por tratarem de questões de minorias ou de retratarem a realidade subjetiva feminina do século XIX ao século $\mathrm{XXI}$ e que por isso, "[...] jamais podiam pertencer ao cânone literário brasileiro, devido a preconceitos de gênero" (BONNICI, 2011, p. 116). Isso se dá pelo fato de que não é de relevância a quem está no poder da sociedade uma Literatura que traz à tona toda a violência física e simbólica que as minorias sofrem no geral. Não é de interesse patriarcal que as mulheres e as outras minorias tenham voz no mundo artístico, inclusive pela escrita, pois "a escrita sempre foi uma forma de poder" (REIS, 1992, p. 67).

Para aquelas escritoras sufocadas por uma crítica misógina e patriarcal era comum que "[...] não ousando inovar, as mulheres submeteram-se aos cânones masculinos. E, imitando-os, para se integrarem na corrente, também não foram reconhecidas nem respeitadas e sim esquecidas, mortas" (MUZART, 1995, p. 81). De outro lado, havia aquelas que também eram apagadas da história por escreverem aquilo que era delas, sua verdade, sendo também julgadas como escrita de "baixo nível estético" (BONNICCI, 2011, p. 144). Dessa forma, o caráter imparcial do cânone é posto aqui em questão, pois, fica evidente os valores axiológicos de seus constituintes que, em muitos casos - se não em todos - são homens, brancos, em cargos de poder, com tendência a catalogar as chamadas minorias em seus arquétipos de qualidade sem reconhecer a sua história marcada por desfalques e preconceitos. 
Isto posto, o que se apresenta aqui é uma discussão sobre questões acerca da recepção crítica de obras literárias de autoria feminina produzidas no Brasil e no exterior, como o caso do corpus de análise, o romance Uma Duas, de Eliane Brum (2011), levando-se em conta os critérios seguidos pelos críticos para estabelecer a qualidade em obras produzidas por mulheres. Além disso, aqui também se faz pertinente e presente uma discussão de todo o processo de escrita catártica das personagens, na qual, elas expõem e denunciam traumas, abusos, e todo o sentimento de impotência diante de um mundo marcado pela violência física e simbólica contra as mulheres.

\section{A emergência da voz das mulheres por meio da escrita literária}

Na história da Literatura como tal e na das bases formadoras da sociedade, é inegável que houve, e ainda há, o apagamento de muitas mulheres que, retomando parte da afirmação do tópico anterior, quando consideradas autoras, foram deixadas à margem do que seria produzir uma obra de qualidade estética, ainda que muitas tenham produzido obras relevantes no cenário da Literatura; todavia, na maioria dos casos, eram produções cuja autoria lhes era negada pela necessidade do uso de pseudônimos masculinos, como é o caso de escritoras do século XIX como a britânica Mary Ann Evans, conhecida até hoje pelo pseudônimo de George Eliot. Não é preciso ir longe em estudos de historicidade para traçar um panorama evidenciando a falta de voz e de representatividade feminina na Literatura como um todo.

Essa invisibilidade feminina se deu por inúmeras opressões e repressões perpetradas pela sociedade patriarcal, dentre as inúmeras limitações ao desenvolvimento intelectual das mulheres, é possível citar a relação quase nula delas com a educação básica, que seguia sendo um monopólio masculino, a falta de recursos financeiros e, consequentemente, a falta de liberdade econômica que Virginia Woolf pontua como sendo de extrema importância para as mulheres que almejavam o ápice da carreira artística. Com efeito, para a autora inglesa, "uma mulher precisa ter dinheiro e um teto todo seu, um espaço próprio, se quiser escrever ficção" (WOOLF, 2014, p. 12). Além disso, se a mulher visava exteriorizar o seu pensamento crítico, as suas emoções mais intimas e subjetivas, ela necessitaria de, no mínimo, independência financeira como já citada e de muita confiança e perseverança em suas ideias, ou seria/ era taxada, no discurso mais aprazível, de "monstro" (WOOLF, 2014, p. 85). Evidenciando o argumento, temse o exemplo de Charlotte Brontë (1816 - 1855), que escreveu, entre outros, o romance Jane Eyre (1847), atuando como uma grande representante dessas mulheres que escreveram textos e livros de qualidade - mesmo que, em muitos casos, a crítica negasse a elas tal feito -, mas que poderiam ter escrito com muito mais rigor estético se tivessem tido a liberdade e o apoio para assim fazer.

Posto que a tendência natural da sociedade é a prosperidade e assim é que se segue em muitos casos (ressalvo as questões envolvendo as minorias que para atingirem a "prosperidade" necessitaram/necessitam de mais do que uma "tendência natural"), muitas das obrigações domésticas e de gênero atribuídas às mulheres, no final do século XIX e começo do século XX, foram perdendo o seu valor vigente e diversos empecilhos ao desenvolvimento cultural e social das mulheres foram, de forma lenta e gradual, superados, como o caso da falta de acesso à educação, contribuindo, assim, com a construção de um lugar na sociedade e de uma maior visibilidade no mundo artístico, posto que ambas as coisas mantém uma estrita relação. Tendo sido iniciado um processo de desconstrução desses elementos que impediam a escrita feminina, eis que o cânone literário, já utilizado, passa a ser um poderoso agente usado pelos críticos com ainda mais rigidez em classificações e avaliações para com as obras de autoria feminina e também de minorias - grupos homossexuais, negros etc.

Ter de fato uma Literatura centrada em questões da mulher, na voz da mulher, é muito ameaçador pelo simples fato de que, visto de um panorama geral, o discurso em si é de domínio masculino, e a verdade proferida no discurso é sempre a verdade de quem tem o controle; logo, é a verdade dos homens para mulheres. É nisso que uma Literatura voltada para o universo feminino tem a oferecer de tão ameaçador, o poder de um local de fala que exponha ou não todas as mazelas de ser uma mulher, que mostre, verdadeiramente, o que é ser mulher, ou ainda, quando se tem uma mulher escritora e uma mulher leitora em muitos casos a forma de se ler Literatura é diferente da convencional masculina, pois, "trata-se de um modo de ler a literatura confessadamente empenhado, voltado para a desconstrução das ideologias de gênero, construídas, ao longo do tempo, pela cultura"(ZOLIN, 2009a, p. 218). É evidente que a questão da alteridade é inexistente quando os críticos do cânone literário tecem as suas "observações" a essa Literatura Feminina.

Vista pelo viés de uma crítica feminina e feminista, a literatura canonizada masculina apresenta "caixinhas", nas quais enquadra as personagens femininas em estereótipos como: i) mulher sedutora/imoral; ii) mulher megera; e iii) mulher-anjo/indefesa; o que se propõem de fato em uma Literatura feminina é a quebra desses estereótipos, mostrando que a mulher enquanto sujeito é dotada de uma individualidade impossível de ser categorizada em estereótipos tão estreitos (ZOLIN, 2009a). Basicamente, o que se busca atingir com um espaço no ambiente artístico 
é a totalidade, é uma "forma a viver uma vida inteiramente humana", reivindicar um lugar na Arte é uma forma de "[...] tocar a unidade e ressonância de nossa fisicalidade, o terreno corpóreo de nossa inteligência" (SHOWALTER, 1994, p. 33). Com efeito, é isso que o cânone crítica, não é a falta de qualidade estética em produções femininas, é o fato de ser uma produção feminina. É isso que causa medo. A emergência, a necessidade de ter presença, de se expressar, de se firmar e se constituir na Arte/Literatura, tem movido e continuará movendo não só as mulheres, mas também as outras classes marginalizadas. Tendo isso em mente é imprescindível que se leia tudo de forma crítica, inclusive a própria crítica.

Nesse sentido, a estudiosa Regina Dalcastagnè (2012), ao abordar o lugar de fala na narrativa contemporânea, em sua obra emblemática Literatura Brasileira Contemporânea: um território contestado, enfatiza que o conceito de representação - que sempre foi um tema chave dos Estudos Literários - atualmente tem sido lido "com maior consciência de suas ressonâncias políticas e sociais" (DACASTAGNÈ, 2012, p. 17). De acordo com a autora, o controle do discurso, ou seja, a negação de voz aos seres excêntricos (mulheres, índios, negros, homossexuais, pobres em geral), sempre relegados à margem e ao silenciamento, tem sido uma questão recorrente nas literaturas de minorias. Para ela, não é apenas o direito a voz que é exigido, mas também o da possibilidade de "“falar com autoridade', isto é, reconhecimento social que o discurso tem valor e, portanto, "merece ser ouvido"' (DACASTAGNÈ, 2012, p. 17). Dessa forma, os seres ex-cêntricos, ao tentarem se inscrever no campo literário, buscam impor a sua perspectiva e sua dicção.

É isso que o romance analisado, da escritora e jornalista Eliane Brum, ao propiciar o acesso à voz a personagens com as suas memórias, não raras vezes, desordenadas e estilhaçadas, faz emergir o discurso de mulheres, com uma dicção própria, em meio ao caos do cenário urbano contemporâneo.

\section{A escrita como catarse e protagonismo em Uma Duas}

O romance Uma Duas, corpus desse artigo, de autoria de Eliane Brum, publicado em 2011, pela Editora Leya, e com uma segunda edição pela Arquipélago Editorial, em 2018, é um representante da nova fase que a Literatura de autoria feminina se encontra. De acordo com Showalter (1985 apud ZOLIN 2009b, p. 330), a Literatura de autoria feminina passou por três fases: a primeira sendo a fase feminina, caracterizada por "imitação e internalização dos valores vigentes"; a segunda fase, a feminista, foi caracterizada por "protesto contra os valores e os padrões vigentes"; e a terceira fase, a qual é possível enquadrar o romance em análise, é a fase fêmea, marcada por "autodescoberta e busca de identidade própria". Isso não significa que questões de gênero não sejam mais relevantes, contudo, outros temas próprios do mundo contemporâneo tendem a aparecer, como a questão dos deslocamentos físicos e identitários tanto de homens como de mulheres, assim como questões mais existenciais tais como a angústia, a depressão e a morte.

Conforme postula o sociólogo francês, Alain Touraine (2011), cuja obra é dedicada à sociologia do trabalho e aos movimentos sociais, a mulher contemporânea busca uma libertação do pensamento retrógrado de "ser para o homem" (BEAUVOIR, 1949 apud TOURAINE, 2011, p. 16) e passa a ser para ela, a se reconhecer enquanto mulher e buscar ser livre de todos os pressupostos patriarcais que esse termo "mulher" carrega, ou seja, "elas existem primeiramente por elas mesmas e para elas mesmas. E essa afirmação é mantida mesmo quando elas têm consciência de sua dependência" (TOURAINE, 2011, p.29). Em seu trabalho, o autor evidencia historicamente as lutas e as conquistas das mulheres, em especial, das feministas. De acordo com ele, o pensamento arcaico, regido por uma concepção machista sobre as mulheres, foi aos poucos derrubado. E, assim, direitos foram assegurados e a figura feminina passou a desempenhar papéis importantes na sociedade e na arte. Fica evidente que "[...] ser ou não respeitada é uma questão ideológica" (MUZART, 1995, p. 86). A partir dos questionamentos oriundos do movimento feminista, a mulher contemporânea também caminhou e ainda caminha para um novo rumo, que é o da conquista de uma subjetividade, como argumenta Touraine (2011, p.46):

Se a identidade das mulheres lhes é dada pelas representações que os homens e as instituições dominadas por eles têm delas, a ideia de uma construção de si de uma mulher não tem nenhum sentido. Isso porque a lógica da dominação que elas sofrem é antes de tudo a privação da subjetividade, o que justifica a importância primordial da afirmação já descoberta: "Eu sou uma mulher", pois esse "eu" está em ruptura com todas as definições "funcionais" das mulheres.

Visto o argumento exposto, é possível concluir que ser uma mulher tem sido, ao longo dos séculos, um objeto definido por outros - por homens - eles e não elas, estipularam e ainda estipulam o que é ser uma mulher, configurando, assim, essa definição do indivíduo-mulher como uma forma de dominação patriarcal. Entretanto, esse quadro passou e ainda passa por muitas transformações. $\mathrm{E}$ antes de qualquer outra coisa, a mulher encontra-se em 
uma busca pela sua subjetividade roubada e, por muitos anos negada, seja pela forma que ela encontrar. É nesse caminho que a escrita entra como recurso utilizado pelas mulheres para exteriorizar os seus pensamentos críticos e íntimos sobre o meio que as cerca. Nesse sentido, a partir do boom da escrita feminina, nos anos 1970 e 1980 do século XX, começou também a emergir a personagem escritora que, muitas vezes, metaforiza as angústias e mazelas do mundo feminino, trazendo à tona temas $\mathrm{e}$ assuntos que eram (e ainda são) tabus na sociedade, como incesto, homossexualidade, eutanásia, violência física e psicológica, automutilação, abuso sexual, dentre outros.

É esse o rumo que o romance Uma Duas, de Eliane Brum (2011), segue em sua trama. A narrativa se dá pela alternância do ponto de vista de duas personagens, mãe e filha, com intensos conflitos no relacionamento. A escrita, com características pós-modernas como a fragmentação textual e a alternância de narradores, é marcada pela cor vermelha, que metaforiza o sangramento devido à violência física e psicológica que assola as trajetórias das personagens femininas. Laura, a filha, começa a escrever capítulos de um livro com seus pensamentos mais conturbados e destrutivos sobre a sua mãe. De uma forma catártica, ela materializa na tela do computador tudo o que ela gostaria que a mãe ficasse sabendo, coisas que Laura jamais teria coragem de dizer. Conforme vai escrevendo e libertando todo o sentimento angustiante que foi contido em seu interior mutilado por anos, ela vai entrando em um processo de incorporação com o que é escrito. Laura, que antes precisava se automutilar para libertar a sua dor, encontra na escrita do livro, uma espécie de lenitivo e, pensando em uma possível linha analítica aos acontecimentos do romance, é viável contemplar a escrita como uma válvula de escape a toda dor que a personagem Laura sente:

Começo a escrever este livro enquanto minha mãe tenta arrombar a porta com suas unhas de velha. Porque é realidade demais para a realidade. Eu preciso de uma chance. Eu quero uma chance. Ela também.

Quando digito a primeira palavra o sangue ainda mancha os dentes da boca do meu braço. Das bocas todas do meu braço. Depois da primeira palavra não me corto mais. Eu agora sou ficção. Como ficção eu posso existir (BRUM, 2018, p. 7).

Nessa perspectiva, é importante observar que o tema do espectro, como imagem obsedante é, segundo Leyla Perrone-Moisés (2016), um motivo recorrente na literatura contemporânea, na qual o tempo aparece menos linear e mais na forma fragmentária da memória das personagens. De acordo com a crítica, "o espectro é o morto mal enterrado, que volta para cobrar alguma coisa mantida em instâncias. Por outras palavras, é o passado que se recusa a morrer" (PERRONE-MOISÉS, 2016, p. 150).

Tanto a mãe quanto a filha são assombradas por espectros de situações traumáticas e mal resolvidas do passado. Por isso, a escrita é a forma de dialogar com o passado e as fissuras provocadas em suas trajetórias. Com efeito, a escrita funciona como uma catarse no sentido aristotélico, purgando-as de seus traumas, suas dores e suas angústias. $\mathrm{O}$ que se nota no romance em foco é que esse processo catártico vai tornando-se algo vivo, quase como uma entidade, e as personagens têm dificuldade em lidar com o que elas escrevem, pois, ora traz alívio, prazer e conforto, ora traz mais dor ainda ao submetê-las a revisitar lembranças dolorosas e espectrais que elas lutaram para enterrar em sua psique, o que se pode evidenciar no desabafo de Laura sobre o poder que as palavras têm em todo o seu ser:

Sempre tive medo de escrever. Da hora de tornar meu sangue símbolo do sangue. Tinha medo por causa da dor desconhecida que talvez viesse, que eu quase podia tocar com certeza. Ainda que eu sangue com sangue, este ritual eu conheço. Ele faz de mim o pouco que tenho de mim. É uma constituição. Me constituo eu pelos cortes em mim. As palavras, não. $\mathrm{O}$ que elas farão de mim?

Me matarão, as palavras? (BRUM, 2018, p. 16).

Analisando sob o âmbito da subjetividade feminina e por seu caráter extremamente novo nas mulheres, é possível estabelecer uma relação entre essa "entidade" criada pela escrita e a própria subjetividade das personagens como algo que se funde perfeitamente. As personagens, mãe e filha, ao escreverem sobre o que sentem, partem em uma jornada de autodescobrimento que é excruciante e causa um profundo estranhamento nelas, talvez por nunca terem tido a consciência de quem elas realmente eram em seu interior mais profundo e subjetivo. Um importante aspecto a ser colocado em questão é que Laura e a mãe tornam-se personagens-escritoras, dando um olhar ainda mais íntimo do que é escrever para salvar-se de si próprio.

No decorrer da trama, a personagem Laura encerra o seu arco com a conclusão de seu livro e declara que "[...] um romance é sempre um filho. Mas é um filho do inferno. E é legião"1 (BRUM, 2018, p. 189), fazendo assim, uma alusão a todos os numerosos sentimentos controversos e destrutivos que ela mantinha inconscientemente dentro de si e que a impediam de seguir em frente, de ser sujeitomulher, dona de si em perfeita plenitude e totalidade. Para

\footnotetext{
Na Bíblia Sagrada o demônio Legião ou Multidão tem uma de suas aparições no Evangelho de Marcos 5. 01-20, quando Jesus se depara com um homem possuído e exige saber o nome da entidade. "Jesus perguntou: como é que te chama? Ele respondeu: o meu nome é Multidão, porque somos muitos" (MARCOS, 5:9, p. 1210).
} 
corroborar com essa reflexão, é relevante recorrer aos estudos de Ruth Brandão sobre a escrita, nos quais, ela afirma que, "escrever pode ser um ato de nascimento ou de renascimento, num lugar único possível para o sujeito, que se esconde no silêncio e deixa as palavras fluírem no branco do papel que as acolhe" (2006, p.24), ou seja, o nascimento desse filho/livro simboliza o nascimento, a libertação do sujeito Laura.

Maria Lúcia, a mãe, condenada a ficar em repouso devido ao câncer que lhe mata lentamente, utiliza a escrita como uma forma de revelar à filha a sua história sombria que jamais tivera a oportunidade de contar, pois, como ela mesma afirma, ela era de "uma dinastia de mulheres destinadas a viver sem palavras" (BRUM, 2018, p. 96). A extremamente complexa, a personagem Maria Lúcia representa o perfil das mulheres oprimidas pelo patriarcado, conforme estabelecido no recorte histórico aqui presente. Ela viveu desde o seu nascimento até meados de sua maioridade, em uma espécie de prisão domiciliar mantida pelo pai - militar e conservador -, no qual, ele justificava tal ato como uma forma de protegê-la dos males do mundo. Contudo, esse confinamento nada mais era do que uma das inúmeras formas de violência contra a mulher, presente no livro e também em muitos lares Brasil a fora.

Vivendo em casa e tendo contato restrito somente ao pai, Maria não tinha conhecimento de mundo. Ela aprendia o que ele queria, ela vestia o que ele julgava adequado, todos os detalhes acerca de quem ela era foram definidos por ele e para ele. Sua educação não contava com estudos filosóficos e sociológicos, pois, tudo isso era nocivo a uma "moça de respeito". A ela era permitido conhecimentos básicos em matemática e português, principalmente, na parte escrita, visto que, sendo o seu pai viúvo, ele fazia com que ela escrevesse cartas destinadas às inúmeras amantes que tinha. O interessante a se notar é que, por ter uma educação moldada ao gosto do patriarcado, Maria sabia ler e escrever, mas não sabia o significado do que lia e escrevia. Com efeito, mesmo não tendo noção do significado das palavras que escrevia, em grande suma de cunho sexual, ela, de certa forma, entendia:

As palavras ardiam em mim. Como é possível alguém que nunca saiu de casa desacompanhada saber que algo era errado? As palavras queimavam meus dedos e abriam sulcos pelo meu corpo, pelas minhas pernas, incinerando a pele por onde passavam (BRUM, 2018, p. 94).

Logo após a morte prematura de seu pai, Maria Lúcia se encontrava em um estado de espírito em que não sabia o que fazer com a sua vida, já que não havia mais alguém para dizer a ela quais seriam os seus passos, suas decisões e as suas obrigações. Isso a tornou um alvo fácil para o porteiro do prédio onde morava com o pai. Esse homem que mais tarde seria o pai de Laura -, simplesmente tomou o controle da vida (e do corpo) de Maria, submetendo-a a uma relação abusiva e destrutiva (para ambos). Devido aos constantes estupros de que havia sido vítima, a personagem recorreu a abortos e a assassinatos das crianças que gerava em seu ventre contra a sua vontade, a salvo Laura que, desde o primeiro instante, chamou atenção de sua mãe por nascer em silêncio. Houve, dessa forma, uma espécie de reconhecimento da condição a que ambas estavam fadadas. Por ter sido vítima de tantos traumas físicos e psicológicos, a personalidade de Mara Lúcia sofreu um profundo condicionamento e todas as suas relações, inclusive com a filha, foram moldadas por acontecimentos traumáticos do passado. Nesse ponto da narrativa, a escrita atua também como uma ponte no conturbado relacionamento de mãe e filha. Uma escreve para a outra as coisas que estiveram por tanto tempo tentando dizer e isso de fato as aproxima.

Feito esse levantamento do passado da personagem com o intuído de aproximá-la da realidade vivida por muitas mulheres que tiveram a sua subjetividade destruída pela figura masculina, agora partir-se-á para um aprofundamento do processo catártico e avassalador que Maria vivenciou com a escrita. Encontrando-se à espera da morte, Maria Lúcia usa um diário como fonte de divertimento (inicialmente), como recurso para passar o tempo, e escrever coisas destinadas à filha, como por exemplo: uma explicação do que a levou a ser uma mãe ruim. Em primeira instância, os relatos feitos por ela, proporcionam uma liberdade nunca antes sentida em toda a sua existência, afinal de contas, é a voz dela, é a visão dela sobre a história dela. Pela primeira vez em sua vida, ela passa a ser protagonista de sua própria história: “O que me interessa agora é contar a minha história. Não a dela. A minha, agora que eu percebi que as palavras me dão um tipo de prazer" (BRUM, 2018, p. 122). Conforme vai escrevendo a sua história e acessando memórias dolorosas e perturbadoras, Maria nota que já não tinha mais filtro do que escrevia, ela percebe que o conforto que ela sentia inicialmente foi substituído por uma dor tremenda e imensurável e ela não conseguia mais controlar o que escrevia, ao que ela mesma admite: "Agora chega. Eu não gostei de escrever dessa vez. Não me fez nenhum bem. [...] Quero dormir sem palavras" (BRUM, 2018, p. 128). Isso tudo serve para conjecturar que o processo de escrita catártico, esse processo de exteriorização, limpeza e purgação, não é tranquilo, ao contrário, é destrutível, pois, é, também, conforme dito anteriormente, um renascimento e, para renascer, é preciso morrer. E tudo isso não é isento de dor e consternação.

Para Dalcastagnè, ao abordar o narrador e as suas circunstâncias na literatura contemporânea, "a 
possibilidade de narrar o passado parece estar estreitamente ligada à ideia de ser autor - e não apenas um ator - dele" (DALCASTAGNÈ, 2012, p. 81). De fato, em decorrência de todo o autoconhecimento obtido pela experiência de escrever, de ter em vista todo o tempo perdido vivendo à luz de pressupostos e mandamentos masculinos é, em seus últimos dias de vida, que Maria descobre que quer viver, pois ela de fato não vivera. De certa forma, a sua narrativa é também, nos termos de Dalcastagnè, uma forma de "burlar seu próprio fim" (2012, p. 81). Com efeito, é pela escrita que ela tem a chance de se conhecer, de se encontrar, de se construir, assim como Laura, sua filha, enquanto sujeito-mulher, uma mulher "para si" como postula Touraine (2011). Mas tendo em mente que o tempo não volta, é escrevendo, é escolhendo a sua última palavra em vida, que Maria concretiza o seu ato mais subversivo, subjetivo e poderoso:

Eu não quero escrever mais. As palavras nunca me fizeram bem, embora eu tenha tido prazer neste diário nos últimos tempos. Mas é o suficiente. Quando sobram, as palavras podem ser imprevisíveis. E não é fácil usar as palavras certas. Se foi uma palavra que matou meu pai, eu quero escolher a última palavra que vou escrever. Agora que eu posso escolher minhas palavras e que elas não mais me violentam. Eu quero que a minha última palavra seja minha. E seja viva, para viver comigo mesmo na minha morte. Para eu saber que fez sentido, que algo fez sentido nesse grande mal-entendido que é uma vida. Para que em meio ao horror de morrer, a esse medo que me domina como o gato que me mastiga por dentro, eu tenha esta palavra para me salvar da escuridão absoluta. A única palavra que eu quis escrever, nascida do meu desejo. Sim, porque você não nasceu porque o seu pai se enfiou dentro do meu corpo paralisado. Você nasceu quando olhou para mim, e eu me vi no seu olhar. E desejei que você vivesse. Você é tudo o que eu sinto de vivo em mim agora que morro (BRUM, 2018, p. 159).

"Laura". Essa é a última palavra que ela escreveu em vida. Escrever havia se tornado algo tão particular da personagem que foi pelo meio da escrita que ela encontrou um propósito de vida. Já não era mais Maria quem havia construído o seu texto, o texto é que a havia constituído enquanto sujeito-mulher. Nessa passagem citada da obra, fica evidente também o perigo que a escrita pode representar quando atinge o caráter de algo vivo, pois, sendo uma "compulsão" (BRANDÃO, 2006, p. 25), é deveras penoso medir o que será escrito e, como confessa a poetisa Rupi Kaur (2017, p. 148), “a questão de escrever é que/não sei se vou acabar me curando/ou me destruindo".

Considerando que a Literatura não é a única área do conhecimento humano que se dedica a estudar questões que envolvem o sujeito, é viável buscar arrojo na
Psicologia, pois tais assuntos subjetivos também se fazem presentes em suas pautas de análise. Focando em um estudo realizado por Sigmund Freud, no final do século XIX, sobre pacientes (mulheres) que eram diagnosticadas prematuramente como histéricas, o professor Freud, ao escolher ouvir os relatos de suas pacientes, cuja "histeria" provinha de abusos sexuais e violência doméstica, concluiu que contar o que havia acontecido era um dos caminhos mais eficientes para atingir uma possível cura, se é que exista cura para abuso sexual e violência doméstica, essas cicatrizes tem tendência a perdurar eternamente no sujeito que as sofreu (SOLNIT, 2017).

Dalcastagnè, ao lembrar do embuste narrativo de Dom Casmurro, de Machado de Assis, nos alerta a desconfiar da figura do narrador, pois, segundo ela, os narradores que frequentam a literatura contemporânea são "narradores suspeitos", com "consciências embaçadas" e que, não raras vezes, possuem interesses precisos que desejam defender, fazendo com que nos comprometamos com seus pontos de vista. Contudo, é fundamental ressaltar que, na ficção contemporânea de autoria feminina, a emergência desses/as narradores/as ex-cêntricos/as nos levam a um olhar sobre o outro feminino que teve a voz silenciada por um discurso autoritário e opressor. Dessa forma, as conarradoras de Uma Duas, com suas narrativas tão viscerais e dilaceradas, mostram a forma que se situam em um mundo caótico e ainda marcado por profundas disparidades entre homens e mulheres. E, nesse sentido, concordamos com Dalcastagné que, ao analisar narradores/as de romances contemporâneos, afirma que "sendo donas de seus passados, essas personagens teriam poder de gerenciar seu presente, e mesmo seu futuro, seja lá o que isso queira dizer para cada uma delas" (DALCASTAGNÈ, 2012, p. 81).

À vista disso, é notável essa "cura" pela interlocução nas personagens do romance Uma Duas (2011), cada qual lidando com as suas batalhas interiores, exorcizando os seus próprios demônios, encontrando caminhos em meio a desilusões. Tendo voz ao escrever o que jamais poderia ser dito oralmente, mãe e filha se reencontram, se redescobrem, se constituem enquanto Sujeitos e Mulheres.

\section{Considerações finais}

As considerações acerca da escrita catártica e como ela atua como um meio para a constituição da subjetividade feminina que se fazem expostos neste artigo têm em vista contribuir com o escopo teórico de estudiosos literários que se pautam nessa vertente da subjetividade. A temática posta em análise é pertinente por seu caráter atemporal e por oferecer espaço a personagens mulheres que tiveram, por muito tempo, a sua voz negada e a sua subjetividade 
destroçada, assim como, milhares de mulheres ao redor do mundo que fizeram e continuam fazendo da Literatura a sua voz e o seu lugar na sociedade.

Nesse sentido, a escrita catártica não figura apenas como uma forma de exteriorização e libertação da condição de dominada. O que se vê no romance Uma Duas é o que Showalter citando Ardener, chama de "espaço selvagem", ou "espaço feminino", que consiste basicamente em uma "zona selvagem da cultura das mulheres espacial, experimental ou metafisicamente [...] significa os aspectos do estilo de vida feminino que estão do lado de fora e diferenciam-se daqueles dos homens" (SHOWALTER, 1994, p.48), ou seja, em Uma Duas, a escrita funciona como um universo próprio de domínio feminino, no qual, apenas assuntos que se relacionam com as questões femininas de subjetividade têm relevância. Livros que tratam de um "espaço unicamente feminino" se fazem cada vez mais necessários ao público, principalmente o feminino, pois, além das questões de representatividade feminina, ter o seu espaço retratado na Arte, sem ser com base em estereótipos e sim com base em sujeitos que escrevem para sujeitos, mulheres que escrevem sobre mulheres e para mulheres, é "tornar visível o invisível, fazer o silêncio falar" (SHOWALTER, 1994, p. 49).

Estudar aspectos de constituição do sujeito pelo âmbito da Literatura se mostrou uma experiência de autoconhecimento enriquecedora e torturante, pois, é pelo olhar de mulheres vítimas das mazelas do patriarcado, pelo olhar de mulheres que tiveram a sua condição de sujeito negada, que podemos visualizar os efeitos destrutivos do que é ser para o outro, do que é não pertencer a si mesma. Por fim, o olhar analítico utilizado no corpus representa uma das possíveis abordagens a serem seguidas para futuras análises da temática e do romance.

\section{Referências}

BÍBLIA. Português. Bíblia Sagrada. São Paulo: Sociedade Bíblica do Brasil, 2009.

BONNICI, Thomas. O cânone literário e a crítica literária: o debate entre a exclusão e a inclusão. In: BONNICI, Thomas; FLORY, Alexandre Villibor; PRADO, Márcio Roberto do Prado (org.). Margens instáveis: tensões entre teoria, crítica e história da literatura. Maringá: Eduem, 2011.

BRANDÃO, Ruth Silviano. A vida escrita. Rio de Janeiro: 7 Letras, 2006.

BRUM, Eliane. Uma duas. 2. ed. Porto Alegre: Arquipélago Editorial, 2018.

CANDIDO, Antonio. Vários escritos. Rio de Janeiro: Ouro Sobre Azul, 2011.
DALCASTAGNÈ, Regina. Literatura Brasileira

Contemporânea: um território contestado. Vinhedo:

Horizonte, 2012.

KAUR, Rupi. Outros jeitos de usar a boca. São Paulo: Planeta, 2017.

MUZART, Zahidé Lupinacci. A questão do cânone. Anuário de Literatura, n. 3. Florianópolis: [S.n.], 1995.

PERRONE-MOISÉS, Leyla. Mutações da Literatura do século XXI. São Paulo: Companhia das Letras, 2016. https:// doi.org/10.4067/s0718-22952018000200400

REIS, Roberto. "Cânon". In: JOBIM, José Luís (org.). Palavras da crítica. Rio de Janeiro: Imago, 1992.

SOLNIT, Rebecca. Os homens explicam tudo para mim. São Paulo: Cultrix, 2017.

SHOWALTER, Elaine. A crítica feminista no território selvagem. In: HOLLANDA, Heloísa Buarque de (org.). Tendências e impasses: o feminismo como crítica da cultura. Rio de Janeiro: Rocco, 1994.

TOURAINE, Alain. O mundo das mulheres. 3. ed. Petrópolis, RJ: Vozes, 2011.

WOOLF, Virginia. Um teto todo seu. São Paulo: Tordesilhas, 2014.

ZOLIN, Lúcia Osana. Literatura de Autoria Feminina. In: BONNICI, Thomas; ZOLIN, Lúcia Osana (org.). Teoria Literária: Abordagens históricas e tendências contemporâneas. 3. ed. Maringá: Eduem, 2009a.

ZOLIN, Lúcia Osana. Crítica Feminista. In: BONNICI, Thomas; ZOLIN, Lúcia Osana (org.). Teoria Literária: Abordagens históricas e tendências contemporâneas. 3.ed. Maringá: Eduem, 2009b.

Recebido em: 22/1/2019.

Aprovado em: 11/11/2019.

Publicado em: 21/12/2019.

\section{Autoras:}

Natacha dos SANtos Esteves

Graduanda do curso de Letras Português/Inglês, da Universidade Estadual do Paraná/campus de Campo Mourão, Paraná, Brasil. É bolsista do $\mathrm{PIBIC/CNPq}$, com o desenvolvimento da pesquisa "A subjetificação feminina por meio da escrita: uma leitura do romance Uma Duas, de Eliane Brum", orientada pela professora Wilma dos Santos Coqueiro. Orcid: https://orcid.org/0000-0002-9834-5044

E-mail: natachaestevescm@gmail.com

Endereço: Universidade Estadual do Paraná

Av. Comendador Norberto Marcondes, 733 - Centro

87302-060, Campo Mourão, PR, Brasil

Wilma dos SANTos CoQueiro

Doutora em Letras, Área de concentração em Estudos Literários, pela Universidade Estadual de Maringá. Docente adjunta na área de Literaturas de Língua Portuguesa do colegiado de Letras da Universidade Estadual do Paraná, campus de Campo Mourão, Paraná, Brasil.

Orcid: https://orcid.org/0000-0001-6271-4744

E-mail:wilmacoqueiro@gmail.com 